\title{
An Approach about Health Games to Social Network Environment
}

\author{
Anabela Pinho \\ Departamento de Informática e Matemática \\ Instituto Politécnico de Bragança - EsACT \\ Mirandela, Portugal \\ apinho@ipb.pt
}

\author{
Hugo Paredes \\ Departamento de Engenharias \\ Universidade de Trás-os-Montes e Alto-Douro \\ Vila Real, Portugal \\ hparedes@utad.pt
}

\author{
Nelson Zagalo \\ Departamento Ciências da Comunicação \\ Universidade do Minho \\ Braga, Portugal \\ nzagalo@ics.uminho.pt
}

\begin{abstract}
The need for contact, sharing and socializing is part of human nature, so that the community's role is vital to the survival of the species. With the development of Information and Communication Technologies and their influence on society and everyday life, led the search for new ways to build relationships and create communities among people, creating virtual communities; turn social networks emerge as new forms of association that respond to more complex understanding of human interaction in a way that the wider community; these to promote your main goal, more integrated into the games as a tool of socialization. The impact of current games at various levels, as the social and economic development, and its applicability in various fields, it becomes important to analyze the contribution of the community. It is intended in this article, a description of the factors that motivate this research to a later stage to develop the proposed objectives: to analyze the new social reality and develop a model that allows adapting the health games to social games in order to foster the creation / sustainability of communities based on social networks, aiming to raise awareness of health issues, increasing knowledge and sharing of experiences of members of communities.
\end{abstract}

\section{Keywords: Communities; Social Networks, Health Games}

\section{INTRODUCTION}

The human being is by definition a social being, as such, there remains a need for sharing, contact and socialization. Apart from rare exceptions cannot live alone, hence the group, the community are vital to the survival of the species. With the development of Computer-Mediated Communication (CMC), new forms of community, namely the Virtual Communities (VC). Due to the changing concept of community, it becomes necessary to understand these new forms of association immersed in the complexity called the Social Network. Social Networks (SN) emerged as the answer to the understanding of human interaction in a broader sense than the community. Its main role is to foster communication and interaction between people. In order to keep alive his main goal - to socialize, have integrated the games as a powerful tool for this purpose.

Currently the games are no longer seen only as a leisure activity and have become a means of developing physical and mental skills, acquiring knowledge and experiences, visual or motor coordination, as well as a means of socialization. Of the various types of existing games, the Serious Games (SG) are used to identify the games for a specific purpose, or that go beyond the idea of entertainment and offer other kinds of experiences, including learning and training, given the benefits identified are being applied in various fields of knowledge, and the health of them. Given the importance to society of this area and due to the fact that more people are dedicated to games, while taking refuge in social systems, the challenge lies in adding this type of games (health games) a social component to greater integration into society, while providing the skills and abilities to players being able to react to certain situations and symptoms.

\section{COMMUNITIES VS VIRTUAL COMMUNITIES VS SOCIAL NETWORKS}

Given the main characteristic of the human being does not live alone, make this a social being, with innate condition for bonding, affects and consequently socializing. The creation of communities and live in them and comes from prehistoric times; The concept of community is used to describe a group of people of a certain geographical area associated with a social structure, may also exist a spirit of sharing among its members and a sense of belonging to the group. The sociologist Ferdinand Tönnies, has created a dichotomy to describe two types of social organization: gemeinschaft (community), describes a traditional society, homogenous culture, where individuals have interpersonal relationships and value the personal relationships; gesellschaft (association), characterized by society urban industrialized, describes the set of individuals with impersonal relations, distant, and individualized using social relations as a means to an end[1].

With the emergence of CMC and its influence on society and everyday life, led the search for new ways to build relationships and create communities among people, giving rise to new forms of community, namely the $\mathrm{VC}$, allowing groups of people to establish social relations among themselves, which remain long enough so they can build a team organized through the Internet. According to analysts of networks, these new forms of community, pointing to the need for a change in how we understand the concept. If we focus directly on social ties and informal systems of exchange of resources, instead of focusing on people living in neighborhoods and small towns will have an image of interpersonal relations is very different from the one we are used. This fact leads us to change the concept of community to social network. Aspects such as solidarity, neighborhood and kinship prevailed when it defined a community, nowadays, are just a few among the many possible patterns of Social Networks (SN). The VC is a new way of making society. The VC people use words through the screen of the monitor to exchange experiences, discuss, engage in intellectual discourse, exchange feelings, develop friendships, play, make art, etc. The participants just cannot touch it or assaults. These communities have become attractive and even addictive, causing many to turn into virtual relationships as real. Rheingold suggests 
that if the VC meet the social needs of people, then they should suffer a significant growth in coming decades. The $\mathrm{CMC}$ is the means for the formation of VC. In these participants create ways of analyzing reality, changing the conventional social styles, through the emergence of new communities and cultures. Cyberspace is not a cold place, as it may seem to some visitors or theoretical, where there are only accurate information, pre-programmed by computers. Technological development has also brought new forms of socialization, even if that socialization is not face-to-face. Due to the changing concept of community, it becomes necessary to understand these new forms of association immersed in the complexity called the Social Network. The SN responds to an understanding of human interaction in a broader sense than the community [2][3][4][5][6].

The aim of $\mathrm{SN}$ is to join groups of people who want to interconnect by one or more factors including needs, interests, and practices. In turn, access people to $\mathrm{SN}$ to communicate because they see tangible benefits (and some intangibles). These tend to operate as networks of relationships in the real world. They let read news, discuss issues of work and private life, share their ideas and experiences and have access to knowledge that would not have access otherwise.

The Social Network Sites (SNSs) are Web-based services that enable individuals build a profile public or semipublic within a limited system, joining a list of other users with whom you share links, and browse through this list, see and traverse the links of those users within the system. The first SN was established in 1997 and currently there are hundreds of networks around the world, supporting practices, interests and diversified users. One of the biggest SNSs is Facebook, created in February 2004, being the most common SN at the moment. One strand of current research focuses on the consequences of using Facebook; Among young adults, the relationships become important, both for generating offline benefits, known as social capital or to the psycho-social development. Social capital is an elastic construction used to describe the benefits that accrue from relationships with others. The present identity on Facebook acquires a new status, which allows you to serve as an indicator of what is real or not. So we now live in a hyperreality in which the image (Facebook profile) is the reality, and that the real assumes little or no value. Thus we created a problem which is that we need to keep tight control of virtual identity, otherwise we may suffer real consequences. In this context is not unnecessary to treat our physical image to socialize, we need to keep our virtual presence as something that can represent us and to represent our goals. Thus, the $\mathrm{SN}$ can be seen as a way to combat isolation in the real world, approaching similar individuals with converging or interests relationships, who adding the games as a powerful tool of socialization, bringing them a "new life". The Facebook linked games to its platform, making other social platforms to follow, like MySpace and Hi5. The success pointed to these games has undoubtedly its socializing aspect, by using strategies that encourage interaction with friends who meet in the real world [7] [8].

\section{THE ROLE OF GAMES IN SOCIAL NETWORKS}

The games included in the SNSs, are called social games. Don't are new types of games, but rather a recovery of ideas and habits present in the cultures of physical communities and their development was based on design templates of various types of existing video game. The integration of digital games in a social networking platform, is itself the source of all innovation in these games, once the platform don't serves only as a repository like a gaming portal, but serve independently the functionality of the game. This means that social games operate using the information in this platform systems, without which the overall design of the game would collapse. In this sense it is not the player looking the game, but it is the platform that the indicates according to his profile on the social network [7]. The virtual environment of these games, as well as discussion forums and presential events, facilitates the creation and development of communities of players; They need to interact with each other to perform tasks and / or complete objectives, as a rule, create groups and consequently VC players, making this environment a "space" of choice for the establishment of friendship or obtaining relationship.

\section{SERIOUS GAMES AND HEALTH GAMES}

Currently, the games don't are just a longer source of motivation but became as a means of development physical and mental skills, visual and motor coordination, skills and strategies, as well as a means of socialization, leaving to be only understood as an activity playful. Many studies show the different areas where we can apply and use the games, so it is presumed that his popularity will not diminish, partly because of the increasing number of players, and secondly, the growing interest among companies in digital entertainment have been engaged in the development of content and solutions available online multi-player games, contributing to the relevance of these environments [10] [11].

There are several types of games: action, adventure, educational, combat, simulators, entertainment, among others, there are still others that are designed using features present in more than one of these types mentioned above, dubbed the Serious Games (SG). These are fundamentally aimed at simulation the practical situation day-to-day, with the aim of providing professional training, critical situations in companies, raise awareness children, youth and adults, and also trivial situations, the mission make the simulations even more attractive and entertaining, while offering activities that promote the absorption of concepts and psychomotor skills. Thus, they are used to identify the games for a specific purpose, ie that go beyond the idea of entertainment and offer other kinds of experiences, including learning and training; are being applied in various fields of knowledge, being a health of the sectors that has benefited from its use [11] [12] [13].

The difficulties encountered in obtaining materials, product validation and training of personnel, as well as the need for new approaches to rehabilitation and education 
of healthy habits, make the games an important ally of education, training and simulation to health, benefiting professionals and patients. The SG for health are designed to entertain players, while they try to modify some aspects of their health behavior [14]. Surveys conducted have shown that learning becomes effective when the virtual games are used for education and training, in addition to having effective transfer of acquired knowledge to real environments. These games are full of situations where the player is faced with the decision-making to apprehend a lesson or live an experience [15].

This type of game requires planning and a multidisciplinary team in its construction. Several areas of knowledge, works in an interdisciplinary way with the industry of SG. In health area, there are several applications that stand out with diversified features(listed by category):

- Therapy auxiliaries: This type of games are designed for people undergoing rehabilitation and physical or psychological treatments. The most popular applications are for the treatment of phobias, such as fear of heights, public speaking, insects, etc. Try to reproduce situations of fear, gradually introducing them in the midst of other situations, in order to accustom the user through experience (practice).

- Promotion of health and fitness: examples of these games, are the MindHabits ${ }^{1}$, whose goal is to allow the player to conduct exercises and activities to maintain positive attitudes and reduce the stress of day-to-day. The Incredible Adventures of the Amazing ${ }^{2}$ Food Detective, to teach to encourage good eating habits. There are even games designed to teach work safety and what to do in emergencies, others that focus on the achievement of safe attitudes in traffic, others seeking to encourage elderly people to perform exercise through dance, using a special mat that shows the position steps and recognize them for score $^{3}$. In dentistry, the games are targeted to a young audience by addressing concepts related to diet and oral hygiene, in order to teach best practices to prevent tooth decay and a guide to brushing, whose outstanding feature is the presence of playful elements to motivate and stimulate learning of the smaller, and some of them include education for mothers. Others still, developed for the prevention and instruction of behaviors necessary for the treatment of asthma and diabetes aimed at children. The games has a story and the characters are affected by the disease (asthma or diabetes), it's up to player know how to treat the disease, through tasks like, making sure the daily dose of medication, make correct decisions regarding the choice of appropriate places or of a balanced diet, measure to glucose levels, or use an inhaler at the right time, etc., through these situations the player learns to react to these diseases, acquiring information about them and care they should have.

- Monitoring health: through the provision of biological sensors, have been used to observe the brain increased

\footnotetext{
${ }^{1}$ http://www.mindhabits.com

2 http://www.members.kaiserpermanente.org/redirects/landingpages/afd/

${ }^{3}$ http://www.humanagames.com
}

activity in people when exposed to games, towards understanding the effect on these people.

- Training and simulation: the aim is to provide facilities for training, through playing real situations. A system of training in acupuncture uses a virtual human who considers the depth and position of each of the contact points considered in this type of treatment is used, a specific device with sensors to simulate a real needle, the system provides a trial run of the procedures in real time. In this category, there are several games that simulate surgeries, eg, a game ${ }^{4}$ that teaches the steps of a heart surgery, allows the user to learn the tools and steps involved in this type of procedure, and need to comply with specific steps to receive a score. Also in dentistry, there are SG targeted at students and professionals, these games invest in realism with different motives, some simulate scenarios, and virtual patients by allowing players to chat and make a diagnosis like a real consultation, other through mechanisms of interaction, allow the players feel properties like, density, strength return and endurance of the oral cavity.

These are some of the many projects on SG applied to health. Currently there are many partnerships for projects development involving companies, researchers and professionals from various fields to share information on impact what games and game technology can have in solving problems in health and policies necessary [14] [16] [17 ] [18] [19] [20].

The relevance of this study in the future, relates to understanding what a social game can do for your community, and through it help to create communities and / or its maintenance. There is literature that demonstrates the importance of communities through their practices in support of certain diseases, highlighting the role that VC can play for its members on solutions to health problems. Online Communities for Healthcare $(\mathrm{OCH})$, often exist in the form of interactive health communication applications, providing health information with a least one of the following features: social support, decision support and behavior change support. At present, the most common forms of social behavior in $\mathrm{OCH}$ are seeking and sharing personal experience, opinions and answers, and providing support and empathy [21].

The increasing interest in Internet and $\mathrm{SN}$ have made more people inquire about health-related information via virtual environments, seek out advice, exchange experiences and support from online peer networks [22]. With the role of the Internet as a platform for SN, typified by the growing interest in sites like Wikipedia, Facebook and MySpace, we can envisage more consumers seeking health-related information and advice from online peer networks [21].

Many e-health communities representing many areas of health services have spread over the Internet. "Cancer.net: Making a world of difference in cancer care" (http://www.cancer.net/portal/site/patient), is an example of a cancer e-health community that provides a place where cancer patients and survivors, professionals and

\footnotetext{
${ }^{4}$ http://www.abc.net.au/science/lcs/heart.htm
} 
experts or subgroups can share information and care. Ehealth communities differ from regular websites. Websites can provide information to users but e-health communities are more to personal resources which allow users to get more like face-to-face situation where members in the group can interact with others who shared similar problems. "The Wellness Community, which provides "cancer support, education and hope" (http://www.thewellnesscommunity.org/mmlcommunity.a spx), is another example of an e-health community that provides emotional support, care and a forum for people in the community to share the same health concerns as the cancer survivors [22].

Healthcare consumers' social networks play a key role in their progress through healthcare journeys, and are vital sources of advice, recommendations, empathy and support. This has already been recognized on the Internet by the establishment and popularity of online healthcare consumer communities [21].

Thus, if we associate the health games a social component, they may be accessed via the $\mathrm{SN}$, so that members can have easily and intuitively access to these games to help their diseases by increasing knowledge, sharing of experiences and help other members, promoting sustainability and / or creation of new communities.

\section{CONCLUSION AND FUTURE RESEARCH}

With this article, we intended to submit a brief description of the actuality concerning a dichotomy Communities and $\mathrm{SN}$, as well, as understanding how and why so many social experiments are currently evolving in parallel with the latest communication technologies. In this emerging social reality, we find that a social trend as influential as the "gaming", cannot be easily removed from the agenda of the future. Thus, the games will penetrate, in a more comprehensive, in the world of culture, the work and science. The scope of "Serious Gaming" has the potential to become one of the ways of acquiring core knowledge of the XXI century. For all this, we should focus on investigation of positive features and the exhaustive exploration of potentialities social and political the games; In our case, the study focused on health games.

The interest of this work, relates to two factors, firstly, the present moment the community and their emergence within the SN on the Internet, on the other hand, the fact that currently the $\mathrm{SN}$, and inherently the VC to them associated, often have their survival associated to the games. The games come add to these communities an more "tool of interaction", potentiating its users to new forms of interaction and achieve the goals of the community. From this theoretical approach, we intend in a future works, integrate two areas of impact, social and health, proposing a model that adapts games with health objectives in social games to determine how they can help create or sustain virtual communities based on SN. To create the model is necessary deepen study on the creation of VC, as well of SN and its integration with the games, to better understand the interactions that take place in the networks and with the games.

\section{REFERENCES}

[1] Tönies, Ferdinand, "Comunidade e Sociedade", Textos Selecionados, In: MIRANDA, Orlando, Para Ler Ferdinand Tönies, São Paulo: Edusp, 1995.

[2] Wellman, B. e Berkowitz, S. D., "Social Structures: a network approach", New York, Cambridge University Press, 1988

[3] Rheingold, Howard, "The Virtual Community: Homesteading on the Electronic Frontier", 1993 ,

http://www.rheingold.com/vc/book/intro.html

[4] Rheingold, Howard, "A Comunidade Virtual”, Lisboa, Gradiva, 1996 [5] Fernback, Jan e Thompson, Brad, "Virtual communities: Abort, retry, failure?", 1995, http://www.Well.com/user/hlr/texts/Vccivil.html,

[6] Wellman, Barry e Gulia, Milena, "Net Surfers don't Ride Alone: Virtual Communities as Communities", 1999, http://www.acm.org/ ccp/references/wellman/wellman.html

[7] Zagalo, Nelson, "Novos Modelos de Comunicação Interactiva nos Jogos Sociais", in Actas, VI Seminário Jogos Eletrônicos, Educação e Comunicação. Salvador Bahía, 2010

[8] Steinfield Charles, Ellison Nicole, Lampe Cliff, "Social capital, selfesteem, and use of online social network sites: a longitudinal analysis". Journal of Applied Developmental Psychology, 29, 434-445, 2008.

[9] Lafrance, J-P, "La machine métaphysique. Matériaus pour une analyse dês comportaments dês Nintendo Kids", in Résaux, n 67. Paris: CNET, PP. 9-32, 1994

[10] Torres, A., Zagalo, N., Branco, V., "Videojogos: Uma estratégia psicopedagógica?". In Actas, Simpósio Internacional Activação do Desenvolvimento Psicológico, Portugal, 2006.

[11] Barnes, T., Encarnação, M.L., Shaw, D., "Serious Games", IEEE Computer Graphics and Applications 29(2), pp. 18-19, 2009.

[12] Zyda, M., "From Visual Simulation to Virtual Reality to Games", no 9, IEEEComputerSociety, pp. 2532, 2005.

[13] Blackman, S., "Serious Games... and Less!", Computer Graphics, 39(1): 12-16, ACM, 2005.

[14] Machado, Liliane, Moraes, Ronei, Nunes, Fátima, “Serious Games para Saúde e Treinamento Imersivo". In: Abordagens Práticas de Realidade Virtual e Aumentada, SBC, 2009, http://www.abstech.com/admin/modulos/portal/upload/arquivos/17/serious_games_final .pdf

[15] Johnsen, K., Raij, A., Stevens, A., Lind, D. S., Lok, B, "The validity of a virtual human experience for interpersonal skills education", Proc. SIGCHI Conf. on Human Factors in Computing Systems (CHI '07), pp. 1049-1058, ACM, 2007.

[16] Stapleton, A., "Serious Games: Serious Opportunities", Australian Game Developers Conference, Australia, 2004

[17] Sawyer, B., "From Cells to cell Processors: The Integration of Health and Video", Games. IEEE Computer Graphics and Applications, 28(6):83-85, 2008.

[18] Kanehira, R., Shoda, A, "Development of an Acupuncture Training System Using Virtual Reality Technology", Proc. Fuzzy Systems and Knowledge Discovery Conference (FSKD '08), 4:665 - 668, 2008.

[19] Lieberman, D., "Management of Chronic Pediatric Diseases with Interactive Health Games: Theory and Research Findings", Journal of Ambulatory Care Management, Vol. 24, Issue 1, pp. 26-38, 2001.

[20] Morais, A., Machado, L., Valença, A., "Serious Games na Odontologia: Aplicações, Características e Possibilidades", XII Brazilian Congress of Health Informatics, Brasil, 2010.

[21] Lau, Annie Y.S., Kwok, Trevor M. Y., "Social Features in Online Communities for Healthcare Consumers - A Review", Online Communities, LNCS 5621, pp. 682-689, 2009.

[22] Abdullah, Nor A., Zakaria, Nasriah, "Sociability aspects in e-health community: A Review”, 978-1-4244-6716-7, IEEE, 2010. 